\title{
Effects of grammatical roles and topicality on Vietnamese referential form production
}

\author{
Binh Ngo \& Elsi Kaiser*
}

\begin{abstract}
We conducted two studies on the use of null and overt pronouns and noun phrases in Vietnamese, with a focus on referents' grammatical roles, grammatical parallelism and topicality. Vietnamese overt pronouns differ from English-type languages as they also function as kin terms. The first study investigated narratives and finds that referential form choice is influenced by the grammatical role and grammatical position of the antecedent: When the subject of the current clause refers to the subject of the preceding clause (subject parallelism), we find a high rate of (null and overt) pronouns. Lack of parallelism triggers mostly NPs. When the object of the current clause refers to the object of the preceding clause (object parallelism), we also find more pronouns than in non-parallel cases. Interestingly, null pronouns only occur in parallel cases. Crucially, we find no clear differences in the distribution of null vs. overt pronouns, suggesting that grammatical roles and parallelism have the same effects on both pronoun types. Using passivization to manipulate topicality, Experiment 2 further investigated the null vs. overt pronoun choice and found that pronouns are strongly preferred for topicalized subjects in passives and that null pronouns exhibit a stronger sensitivity to topicality than overt pronouns. To our knowledge, these experiments are the first experimental investigation of a kin-termbased pronoun system.
\end{abstract}

Keywords. reference resolution; pronouns; subjecthood; topicality; grammatical parallelism, Vietnamese

1. Introduction. Previous research indicates that the salience is a crucial factor for referential form choice. It is widely agreed that highly salient entities are subsequently often referred to with reduced referential forms while less salient referents are referred to with fuller forms (e.g. null pronouns > overt pronouns > NPs) (Ariel, 1990; Givón, 1983; Gundel, Hedberg, \& Zacharski, 1993). There are many factors that can influence entities' salience. One well-known factor is grammatical role (e.g. subject vs. object). The grammatical subject is said to be more salient than the grammatical object (Chafe, 1976; Crawley \& Stevenson, 1990). Thus, according to the salience-hierarchical approach, speakers tend to use more reduced referential forms (e.g. pronouns) to refer to subjects while using fuller forms (e.g. NPs) to refer to objects.

The referential properties of null and overt pronouns have received considerable attention in prior work. Generally, languages with both null and overt pronouns come in two types: prodrop languages, which usually have rich subject-verb agreement, and topic-drop languages, which typically lack verb agreement. Prior work on pronoun interpretation in pro-drop languages such as Italian and Spanish has lead researchers to conclude that grammatical roles are crucial for the choice between null and overt pronoun: While null pronouns tend to refer back to preceding subjects, overt pronouns tend to refer to preceding objects (Alonso-Ovalle, Fernández-Solera, Frazier, \& Clifton, 2002; Carminati, 2002).

However, the null vs. overt pronoun distinction appears to be less clear in topic-drop languages. In Chinese and Japanese, both null and overt pronouns tend to be used to refer to the

\footnotetext{
*Authors: Binh Ngo (binhnngo@usc.edu) \& Elsi Kaiser (emkaiser@usc.edu), University of Southern California.
} 
preceding subject (Simpson, Wu, \& Li, 2016; Ueno \& Kehler, 2016). Thus, crosslinguistically, it is unclear whether null and overt pronouns behave differently and how grammatical roles affect use and interpretation of null and overt pronouns.

The effect of grammatical roles is also reflected in parallelism effects. (Chambers \& Smyth, 1998) found that pronouns, at least in English, tend to prefer antecedents in the matching grammatical position: Pronouns in subject position tend to be interpreted as referring back to a preceding subject, and pronouns in object position tend to be interpreted as referring back to a preceding object. However, to the best of our knowledge, work on grammatical parallelism has focused on the comprehension of English pronouns and has not looked at the null vs. overt pronoun distinction in depth.

The finding that subject-position pronouns prefer subject position antecedents may also be related to topicality, as the grammatical subject of a sentence is often also the topic of discourse (Givón, 1983). To tease out the effects of subject preference and topicality, (Rohde \& Kehler, 2014) used passivization to manipulate the likelihood of a referent being the topic while keeping grammatical role constant. In English, it has been suggested that passivization marks the promoted argument (i.e. the grammatical subject) as the topic (Creider, 1979; Davison, 1984). Thus, the subject of a passive sentence is more likely to be the topic than the subject of an active sentence. Since pronouns indicate a continuation of the current topic (Ariel, 1990; Givón, 1983; Gundel et al., 1993), we expect participants to use pronouns more frequently when referring back to subjects of passives than subjects of actives. Indeed, results from (Rohde \& Kehler, 2014) confirmed that pronouns occurred at a higher rate when participants referred back to subjects of passives than subjects of actives, a topicality effect. However, it is not yet clear how topicality can affect the null and overt pronoun choice.

In this paper, we report two studies on Vietnamese examining the effects of $(i)$ grammatical roles (both subject and object) and parallelism and (ii) topicality on speakers' choice of referential forms, particularly on null and overt pronouns. We choose Vietnamese - a topic-drop language - as the language of investigation for two reasons. First, Vietnamese null pronouns can occur in both subject and object positions as shown in example (1b). (Null pronouns are denoted with parentheses in the translation.)

a. Vân nhìn thấy Lan trên đường về nhà.
Vân saw lan on way home
'Vân saw Lan on her way home.'
b. Gọi mấy lần nhưng cô ta không nghe.
Call several time but she not hear
'(She) called (her) several times but she didn't hear (her).'

Second, unlike many other languages discussed in the pronoun resolution literature, Vietnamese overt pronouns are derived from kinship terms. Example (2) below shows how ông 'grandfather' is used as kinship term in (2a), as the head of the NP in (2b), and as an overt pronoun in (2c). Thus, although we will use the term 'overt pronoun' when talking about these forms in Vietnamese, it is important to keep in mind that these are not typical pronouns.
a. $\quad$ Ong
của Lan vừa đến.
grandfather of Lan just arrive
'Lan's grandfather just arrived.' 


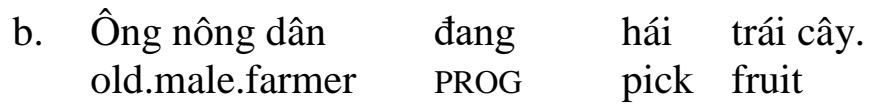
'The farmer is/was picking fruit.'
c. Ông hái từng trái một.
old.male.he pick each fruit at once
'He picked the fruit one by one.'

Furthermore, Vietnamese can provide valuable data that can contribute to the crosslinguistic and typological picture of how null and overt pronouns are used in topic-drop languages. Prior findings show that frequency of pronoun use varies crosslinguistically in topic-drop languages: For example, (Christensen, 2000) found that in Chinese narratives, both null and overt pronouns are used equally frequently. However, for Japanese narratives, (Clancy, 1980) found that while null pronouns are frequent, overt pronouns are rarely used. Thus, it will be interested to see how Vietnamese null and over pronouns behave, considering the complex kinship pronoun system.

2. Experiment 1 - Narrative task. Following (Christensen, 2000; Clancy, 1980), we conducted a spoken narrative experiment to investigate how Vietnamese speakers use different referential forms, specifically null and overt pronouns. Unlike previous studies (Christensen, 2000; Clancy, 1980) which only discussed the overall counts of referential forms, our study focuses on how factors such as (i) grammatical roles and (ii) grammatical parallelism can affect referential form choice.

2.1. METHOD. Twenty native speakers of Vietnamese (living in Vietnam) participated in the spoken narrative experiment. First, each participant was shown the Pear film (Chafe, 1980) about a boy stealing pears. This short film has sound effects, but no spoken words. After watching the film, participants were asked to recount the story as if they were speaking to a friend who had not seen it. The stories were recorded.

2.2. DATA ANALYSIS. The stories were transcribed orthographically. Features of spoken language such as hesitations, pauses, false starts, repetitions and self-corrections were included. Following (Hurewitz, 1998), we define an utterance as a finite clause (i.e. containing a finite verb). Relative clauses are not considered as separate utterances and referents occurring in these clauses are excluded (Bel, Perera, \& Salas, 2010). In this analysis, we only report cases in which referents occur in adjacent clauses. We did not encounter ambiguous pronouns in this dataset.

We coded all singular third-person human referents in adjacent utterances for (i) grammatical roles and (ii) referential forms. Regarding (i) grammatical roles, we coded referents' grammatical roles in both the preceding and the current utterances (e.g. Subject, Object, Possessive, etc.) were recorded. For the purposes of the current work, we only discuss Subject and Object roles in our analysis. Four grammatical configurations were established based on referents' preceding and current grammatical roles as shown in Table 1. Regarding (ii) referential forms, since our goal is to observe how grammatical roles can influence the current choice of referential form (i.e. null pronoun, overt pronoun, and NP), we only coded referents' referential forms in the current utterance. Examples (3-6) illustrate how data is coded with regards to the four grammatical configurations. The referents of interest are in bold. Null pronouns are indicated in the English translations by pronouns in parentheses.
a. $\mathrm{kh}$
cậu bé này đi
when boy
this go past
ngang qua một
con đường
'when this boy went past a road' 
b. thì (Ø) gặp một cô bé cũng đi một chiếc xe đạp then $(\varnothing)$ see a girl also ride a bike 'then (he) saw a girl who also rode a bike'

\section{$\rightarrow$ Configuration: Subject-Subject Referential form: null pronoun}

a. cậu thấy ba cậu bé đang đứng trước mặt mình he see three boy PROG stand front face self

'he saw three boys standing in front of him'

b. một cậu bé đỡ cậu dậy a boy pull he up 'a boy pulled him up'

$\rightarrow$ Configuration: Subject-Object

a. thì $(\varnothing)$ đã đỡ cái cậu bé này dậy then (Ø) PAST pull CL boy this up 'then (they) pulled this boy up'

b. cậu bé này lúc này đau chân boy this time this hurt leg

'at this time, this boy hurt his leg'

$\rightarrow$ Configuration: Object-Subject Referential form: NP

a. thì nó gặp một bé gái đi ngược chiều then he see a girl go opposite direction 'then he saw a girl going on the opposite direction'

b. và do (Ø) mãi nhìn bé gái and because $(\varnothing)$ busy look girl 'and because (he) was busy looking at the girl'

$\rightarrow$ Configuration: Object-Object Referential form: NP

Preceding utterance Current utterance Grammatical configuration

$\begin{array}{lcc}\text { Subject } & \text { Subject } & \text { Subject-Subject (Subject parallelism) } \\ \text { Subject } & \text { Object } & \text { Subject-Object } \\ \text { Object } & \text { Subject } & \text { Object-Subject } \\ \text { Object } & \text { Object } & \text { Object-Object (Object parallelism) }\end{array}$

Table 1. Four configurations based on grammatical roles in preceding and current utterances.

When counting null pronouns, we excluded those that occur in coordinate constructions with "and", "but" and so on. This was done in order to avoid inadvertently inflating the number of null pronouns. Even in languages like English, standardly analyzed as not allowing pro-drop, coordination structures like "Lisa went home and made a sandwich" and "Lisa went to the library but could not find her friend" allow what superficially looks like a missing pronoun/NP. We did not include these kinds of structures in our analyses, in order to make sure that all null pronouns reported in our analyses are 'proper' null pronouns and not analyzable in terms of coordination.

2.3. RESUlts. Let us first look at the overall pattern. Table 2 shows how frequently each of the four grammatical role configurations (summarized in Table 1) occurred in the narratives. Subject position pronouns referring back to a preceding subject (Subject-Subject configuration) are clearly far more frequent than any of the other three configurations. 


\begin{tabular}{cccccc} 
& Subject-Subject & Subject-Object & Object-Subject & Object-Object & Total \\
\hline$\%$ & 78.85 & 5.14 & 9.06 & 6.95 & 100 \\
\hline
\end{tabular}

Table 2: Percentage of each configuration.

Let us now turn to referential form choice (i.e. null pronouns, overt pronouns, NPs) in the current utterance with regard to the four grammatical-role configurations. As seen in Figure 1, the Subject-Subject configuration (Subject parallelism) yields mostly pronouns (null pronouns + overt pronouns $=73.18 \%)$, whereas the other three configurations consist of mostly NPs $(>60 \%$ NPs in each configuration). To examine the pattern of pronoun vs. NP across the four configurations, we conducted a series of chi-square tests ${ }^{1}$. The results suggest that the distribution of pronouns vs. NPs in the Subject-Subject configuration differs significantly from the other three - as one might expect, based on the patterns visible in Figure 1. Specifically, speakers produced significantly more pronouns (null + overt combined) relative to NPs in the Subject-Subject configuration than in the Subject-Object $(\mathrm{p}<.01)$, the Object-Subject $(\mathrm{p}<.01)$, and the ObjectObject configurations $(\mathrm{p}<.01)$. We also compared the use of null vs. overt pronouns in the Subject-Subject configuration, and found no significant difference between the two forms $(p=.13)-$ as the patterns visible in Figure 1 lead us to expect.

Let us now consider the other three configurations, Subject-Object, Object-Subject and Object-Object (Object parallelism) more closely. Overall, they are not significantly different from each other regarding the proportion of pronouns vs. NPs $(\mathrm{p}=.08)$. Intriguingly, we do find that the non-parallel Subject-Object and Object-Subject configurations elicit no null pronouns at all, whereas null pronouns are used $26.1 \%$ of the time in the parallel Object-Object configuration.

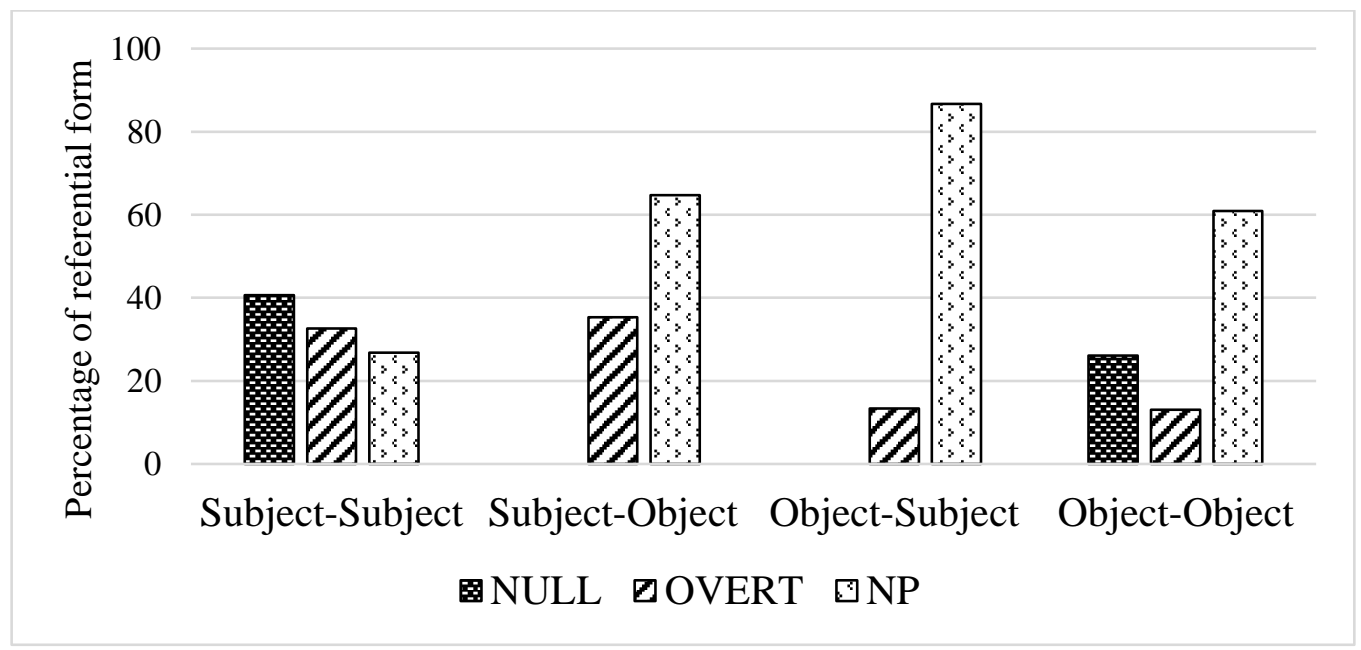

Figure 1. Percentages of referential forms in four grammatical configurations.

\footnotetext{
${ }^{1}$ We used chi-squared test for the statistical analyses in Experiment 1, although we realize that aspects of our data are not ideal for this statistical test. Our elicited-narration technique yielded a corpus of multiple narratives and thus involves multiple observations from each participant. However, our open-ended task differs from the standard, more narrowly-controlled within-subjects design often used in psycholinguistics, and although we have multiple observations from each person, the nature of these observations is highly variable across participants. This, as well as the fact that our analysis of pronominal forms involves analyzing responses dependent on the syntactic configuration that a participant chose to produce, lead us to opt for the chi-squared analysis over other options, although chisquare assumes independence.
} 
2.4. DisCUSSION. Our results show that both subjecthood and grammatical-role parallelism guide speakers' referential form choices in Vietnamese. Specifically, in the Subject parallelism configuration (Subject-Subject), pronouns in general (null pronouns + overt pronouns) are used significantly more than in other three configurations, which have more NPs. We also find hints of parallelism effects partially extending to grammatical objects: The Object-Object configuration elicits use of null pronouns while the non-parallel configurations do not.

Regarding the null vs. overt pronoun distinction, in the two parallelism configurations (Subject-Subject and Object-Object) where both forms are used, we found no clear differences between them. This finding is in line with the findings in Chinese narratives in which speakers used null and overt pronouns equally (Christensen, 2000). However, it is worth noting that in the non-parallel Subject-Object and Object-Subject configurations, participants produced no null pronouns at all, although they did produce overt pronouns. Our results also show that despite the complex kinship pronoun system, Vietnamese overt pronouns are frequently used, unlike Japanese overt pronouns (Clancy, 1980).

3. Experiment 2 - Sentence completion task. As we saw in Experiment 1, in narratives the Subject-Subject configuration is by far the most frequent pattern: Participants tend to produce pronouns in subject position that refer back to a preceding subject. This configuration also exemplifies topic continuity since subjects are often discourse topics (Givón, 1983). Prior work has shown that being the syntactic subject as well as being the topic increases referents' salience (Crawley \& Stevenson, 1990). According to the salience-hierarchical approach (Givón, 1983; Ariel, 1990; Gundel et al., 1993), speakers tend to use reduced referential forms for highly salient referents. This leads to the prediction that Vietnamese speakers would prefer null pronouns over overt pronouns when referring to the highly salient, topical referents. However, contrary to this prediction, we found no clear evidence in Experiment 1 that null pronouns are used more than overt pronouns for subject-position referents. However, Experiment 1 did not directly manipulate referents' topicality. Experiment 2 aims to more directly investigate effects of topicality on Vietnamese null vs. overt pronoun choice.

To manipulate topicality without varying referents' grammatical role, (Rohde \& Kehler, 2014) used passivization, and looked at reference to the subjects of passive sentences (hypothesized to be highly topical) and the subjects of active sentences. Since passivization in English has been claimed to mark the promoted subject as a topic (Creider, 1979; Davison, 1984), subjects of passives are expected to be more salient than subjects of actives, and thus reduced referential forms should be used more frequently to refer back to subjects of passives than to subjects of actives. Results from (Rohde \& Kehler, 2014) confirmed this hypothesis. English speakers used significantly more pronouns when referring back to subjects of passives than to subjects of actives, which can be viewed as a topicality effect. Following (Rohde \& Kehler, 2014), we used passivization as a topicalization device to further examine the null vs. overt pronoun choice in Vietnamese.

3.1. Methods. A sentence completion task was conducted in a spoken format. Thirty-six adult native speakers of Vietnamese (living in Vietnam) participated in the task. Twenty-four target items were created. We used passivization to manipulate topicality; hence, each item has two conditions (active and passive) as shown in example (7). Target items contained two same-gender role nouns (e.g. ông kĩ su' 'male.engineer' and ông lái xe 'male.driver', or cô thơ' may 'female.dressmaker' and cô khách hàng 'female.customer'). The connective vì 'because' was used in all targets, to keep the coherence relation constant. Regarding verb selection, we chose 
twenty-four verbs that we expected to be equi-biased - i.e., to not have a strong bias toward either the preceding subject or object, based on the English norms published in (Hartshorne \& Snedeker, 2013). We tried to avoid verbs with a strong inherent subject or object bias, in order to make it easier to detect potential effects of pronominal form. Thirty fillers were also included.

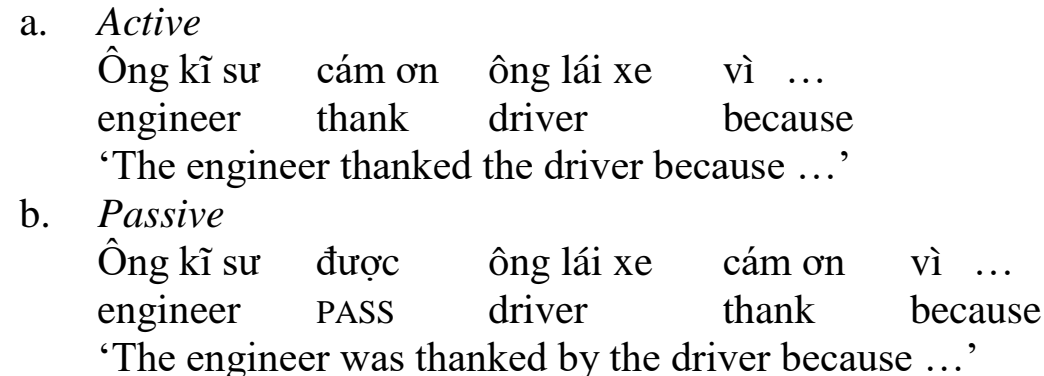

The experiment was conducted on a laptop computer using Paradigm software (Perception Research Systems). Participants were asked to read the sentence fragment on the screen and to think of a natural-sounding continuation. Because the fragment ended at the connective, participants were free to continue however they wanted, and could produce any referring expression (or other kind of word) that they felt would be the most natural way to start their continuation. Once ready, they pressed a key to move to the recording screen. Participants were instructed to say out loud the complete sentence (i.e. both the fragment shown on the screen and their own continuation). The sentence fragment was displayed throughout the recording, in order to avoid imposing a memory burden on participants. After saying the complete sentence, participants pressed a key to move to the next item. This allow participants to proceed at their own pace and to minimize speech disfluencies.

3.2. DATA ANALYSIS. We coded subjects of the continuations (i.e. subjects of the 'because' clause) for (i) referential bias: whether the subject of a continuation referred back to the subject or object of the preceding clause, as shown in Table 3, and (ii) referential form: whether participants used null pronouns, overt pronouns or NPs to refer back to the preceding subject or object. Due to the fact that participants in Experiment 2 were starting a sentence fragment, they always continued with a subject in their continuations. For this reason, we only focus on the subjects of their continuations in our analysis. Thus, Table 3 has only two grammatical configurations ${ }^{2}$, a partial overlap with the four grammatical configurations previously seen in Experiment 1.

Example (8-12) illustrates how data were coded. When it is not clear which referent the subject referred to as shown in (11), we coded the referential bias as 'unclear'. When the subject of the continuation refers to neither the preceding subject nor object as seen in (12), we coded it as 'other'. We excluded both 'unclear' and 'other' cases from subsequent analyses (25.7\% of total data). It should also be noted that Vietnamese has two passive markers, namely duơ c with a positive connotation and $b i$ with a negative connotation as seen in (9-10). We used balanced numbers of each but found no differences between them. Consequently, the two types of passives are collapsed in the results section.

\footnotetext{
2 The Vietnamese passive construction, as seen in (8b-c), is different from English passive in that the demoted argument (e.g. the embroiderer, the chef) does not occur in a by-phrase. This is similar to Chinese passive in which the demoted argument has been argued to be an NP argument of the verb (Huang, 1999). Since our purpose is to investigate which referential form is used to refer to which referent, specifically to the preceding subject referent, we call the demoted NPs of passives 'objects of passives' and do not make further distinction with objects of actives.
} 
Preceding clause

Subject

Object
Continuation

Subject

Subject

Grammatical configuration

Subject-Subject

Object-Subject

Table 3. Two grammatical configurations based on subjects of continuations.

Ông gác cổng kéo lê ông quản lý vì ông ta đã quá say.

male.gatekeeper drag male.manager because he PAST too drunk

'The gate-keeper dragged the manager because he was too drunk.'

$\rightarrow$ Referential bias: Object

Chị dược sĩ

được cô thợ thêu

Referential form: overt pronoun

female.pharmacist PASS female.embroiderer greet because PAST cure

bệnh cho mình.

sickness for self

'The pharmacist was greeted by the embroiderer because $(\varnothing)$ cured the sickness for her.'

$\rightarrow$ Referential bias: Subject Referential form: null pronoun

(10) Ông bác sĩ bị ông đầu bếp khiêu khích vì đã chê món ăn của ông ấy. male.doctor PASS male.chef provoke because PAST criticize dish of he 'The doctor was provoked by the chef because $(\varnothing)$ criticized his dish.'

$\rightarrow$ Referential bias: Subject

Referential form: null pronoun

(11)

Cô thợ may gạt cô khách hàng vì coi thường cốây.

seamtress fool female.customer because look down on she

'The seamtress fooled the customer because (she) looked down on her.

$\rightarrow$ Referential bias: unclear

Referential form: null pronoun

Bác thợ mộc được bác thợ chụp hình liên lạc vì hình đã rửa xong. male.carpenter PASS male.photographer contact because photos PAST develop already 'The carpenter was contacted by the photographer because the photos have been developed.'

$\rightarrow$ Referential bias: other

Referential form: NP

If Vietnamese passives also topicalize the grammatical subject, similar to English passives (Creider, 1979; Davison, 1984; Rohde \& Kehler, 2014), we can formulate two competing predictions regarding the behavior of null and overt pronouns:

- If null and overt pronouns in Vietnamese are both equally sensitive to topicality: Null and overt pronouns will be used equally to refer back to the subjects of active sentences (as we saw in Experiment 1) and also to the subjects of passive sentences.

- If both null and overt pronouns are used for relatively high-salience referents but null pronouns more likely to be used when referring back to topics than overt pronouns: In situations when there are no cues from prior discourse indicating what the topic is, speakers will use null pronouns more often than overt pronouns when referring to the subject of passives (i.e. treating passivization as a cue to topicality), but may use both at equal rates when referring to the subject of actives

3.3. RESULTS. Overall, in the active condition, the Object-Subject configuration occurred more frequently than the Subject-Subject configuration, $69 \%$ and $31 \%$ respectively. In other words, the subject of participants' continuations was more likely to refer back to the preceding object 
than to the preceding subject. In contrast, in the passive condition, participants more likely to refer back to the preceding subject (Subject-Subject configuration: 82\%; Object-Subject configuration: $12 \%$ ).

To examine the rate of null vs. overt pronouns produced by participants in these configurations, we conducted a series of chi-squared tests (see footnote 1). We first compared null and overt pronoun use in the Subject-Subject configuration in active and passive conditions - in other words, when the subject of participants' continuation referred to the subject of the preceding sentence. As seen in Figure 2, in the active condition, speakers showed no preference for either null or overt pronouns ( $\mathrm{p}=\mathrm{n}$.s.) when referring to the subject. Both forms were produced equally often. Crucially, in the passive condition, speakers produced significantly more null pronouns than overt pronouns ( $\mathrm{p}<0.01)$ when referring to (topicalized) subjects.

We also looked at null and overt pronoun use when the subject of participants' continuations referred to the object of the preceding sentence. Although the Object-Subject configuration is not the main focus of this study, it's worth noting that reference to the preceding object in actives and passives (see footnote 2) is equally likely to be accomplished with null or overt pronouns.

As a whole, these results indicate that topicality has an effect on referential form choice in Vietnamese: Although participants were equally likely to use null and overt pronouns when referring back to subjects of actives, they strongly preferred null pronouns when referring to the (topical) subjects of passives.

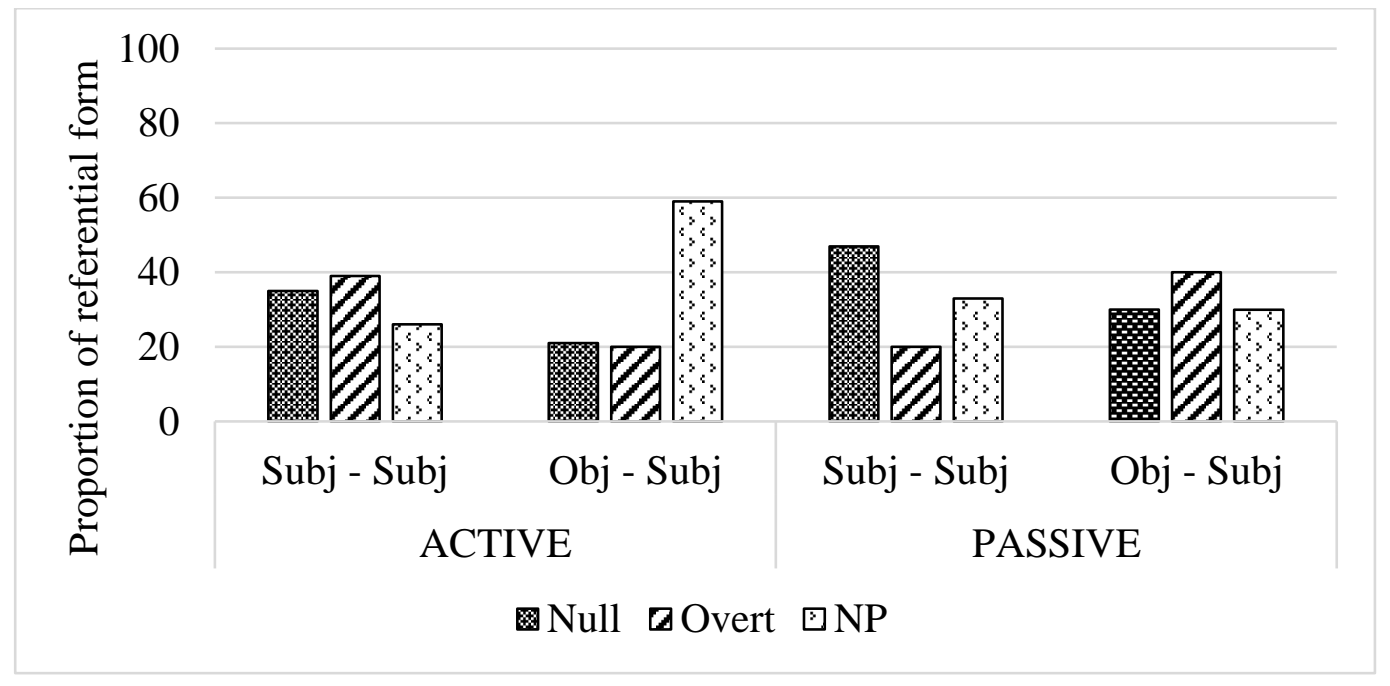

Figure 2. Proportions of referential forms in active and passive.

3.4. DISCUSSION. In this experiment, we investigated effects of topicality - operationalized by means of passivization, building on prior work by Rohde and Kehler (2014) - on Vietnamese speakers' production of null and overt pronouns. We found that topicality can affect speakers' choice of null vs. overt pronouns. While participants have no clear preference for null or overt pronouns when referring back to subjects of actives, null pronouns are strongly preferred when participants referred to the topicalized subjects of passives. It can be concluded that null pronouns in Vietnamese exhibit a stronger preference for topical referents than do overt pronouns.

4. General discussion. We conducted two experiments to investigate how grammatical role, grammatical parallelism and topicality influence Vietnamese speakers' choice of referential 
form, particularly the null vs. overt pronoun choice. In Experiment 1, we asked participants to recount the Pear film and analyzed the spoken narratives. Our analysis took into account referents' grammatical roles in the preceding and current utterances as well as their referential form in the current utterance. This allowed us to examine how grammatical roles and parallelism can affect referential form choice. The results show that both grammatical role and parallelism play a key role in Vietnamese speakers' referential form choice. Specifically, when the grammatical subject role is maintained across clauses (i.e. Subject parallelism), there is a significant increase in pronoun use (null and overt pronouns combined) compared to the other grammatical configurations. Interestingly, there are also hints of a parallelism effect in Object-Object configurations. Although NP use is most frequent in Object parallelism, this configuration yields more pronouns (null and overt pronouns) than the non-parallel ones. Crucially, we found that grammatical role parallelism facilitates null pronoun use: Null pronouns only occur in Subject and Object parallelism configurations. Nevertheless, the overall referential form patterns in Subject and Object parallelism differ from each other, which indicates that grammatical role also matters.

The results of Experiment 1 also show no difference between the two pronoun types. Null and overt pronouns are used equally in Subject and Object parallel configurations. These findings are especially interesting since Vietnamese has a kin-term-based pronoun system; thus, prior to this study, it was not clear how overt pronouns in Vietnamese behave. Our results are in line with previous work in Chinese in which speakers have no preference for either null or overt pronouns in their narratives (Christensen, 2000) and contrasts with results in Japanese in which overt pronouns are only rarely used (Clancy, 1980).

Since Experiment 1 found no difference in null vs. overt pronoun choice with regards to grammatical roles and parallelism, Experiment 2 further investigated whether null and overt pronouns in Vietnamese differ, by taking a closer look at topicality. Previous work has shown that subjects are often topics of discourse (Givón, 1983) and subjects which are also topics are highly salient (Crawley \& Stevenson, 1990). In Experiment 2, we compared how participants used null and overt pronoun to refer to subjects of actives and subjects of passives. Since passivization is known to topicalize the grammatical subject (Creider, 1979; Davison, 1984), we can examine the effect of topicality while keeping the grammatical subject role constant. Following (Rohde \& Kehler, 2014), we implemented a sentence completion task and compared the rates of null and overt pronoun use in continuations after actives and passives. The results show that speakers use null and overt pronouns equally when referring to subjects of actives. In contrast, when referring to subjects of passives, speakers produce significantly more null pronouns than overt pronouns.

The results of Experiment 2 indicate that topicality has an influence on speakers' choice between null and overt pronouns in Vietnamese. It may initially seem surprising that Experiment 1 found no clear differences between null and overt pronouns, although the Subject-Subject configuration in Experiment 1 could be construed as a topic chain situation where we might expect to see topicality effects. However, the lack of topicality effects on null vs. overt pronoun use in Experiment 1 may be due to several factors.

First, let us consider the way in which potential topicality is signaled in the Subject-Subject parallelism configuration and in passives. In Subject-Subject parallelism configurations, the second subject is likely to be a topic but does not have to be one: Being the grammatical subject does not always entails being a topic (Lambrecht, 1994). In contrast, in Experiment 2, the passive structure (more) explicitly signals that the subject is a topic. Thus, it seems reasonable to conclude that being the subjects of a passive is a clearer cue to topic status than being a subject in a Subject-Subject topic chain. In light of this asymmetry between Experiments 1 and 2, it is 
not surprising that we found null/overt pronoun differences in Experiment 2 but not in Experiment 2. If this reasoning is on the right track, our results suggest that Vietnamese null pronouns are more sensitive to topicality than overt pronouns, specifically when the topic of discourse is clearly marked.

Another factor that may give rise to different results between the two experiments has to do with coherence relations. Previous work has shown that how participants comprehend and produce pronouns is influenced by the type of coherence relation (Kehler, 2002; Kehler \& Rohde, 2013). While the narratives produced in Experiment 1 involve different types of coherence relations, in Experiment 2 all targets involved an Explanation relation (due to our intentional use of the connective 'because'). Consequently, the lack of topicality effects in Experiment 1 may be due to the fact that coherence relations are not taken into account in the current analysis of the Experiment 1 data. We aim to disentangle these factors in future work. In addition, the results of Experiment 2 currently only focus on subjects of the continuations. In the future, we plan to also examine the objects in the continuation sentences (when present).

In sum, our studies show that grammatical role, grammatical parallelism and topicality are important factors which influence Vietnamese speakers' choice of referential form. By looking at null and overt pronouns in subject and object position, we obtain novel findings showing effects not only of subjecthood but also of grammatical role parallelism on null pronoun use. These results highlight the importance of considering referents' grammatical roles in sequences of utterances when investigating referential form use. While grammatical roles and parallelism have similar effects on both Vietnamese null and overt pronouns, topicality has a significantly stronger influence on null pronouns than on overt pronouns. Interestingly, despite the fact that Chinese, Japanese and Vietnamese are all topic-drop languages, overt pronoun use varies crosslinguistically. Although Vietnamese overt pronouns are complex kinship terms, speakers do not shy away from using overt pronouns, in contrast to what is seen with Japanese overt pronouns which are historically derived from nouns (Hinds, 1983). Instead, overt pronouns in Vietnamese are used as frequently as null pronouns - similar to what has been observed in Chinese. Finally, to our knowledge, these experiments are the first psycholinguistic investigation of a kin-termbased pronoun system.

\section{References}

Alonso-Ovalle, L., Fernández-Solera, S., Frazier, L., \& Clifton, C. 2002. Null vs. overt pronouns and the topic-focus articulation in Spanish. Italian Journal of Linguistics 14. 151170.

Ariel, M. 1990. Accessing noun-phrase antecedents. London: Routledge.

Bel, A., Perera, J., \& Salas, N. 2010. Anaphoric devices in written and spoken narrative discourse: Data from Catalan. Written Language and Literacy 13(2). 236. https://doi.org/10.1075/w11.13.2.03bel.

Carminati, M. N. 2002. The processing of Italian subject pronouns, Ph.D. dissertation, University of Massachusetts, Amherst.

Chafe, W. 1976. Givenness, contrastiveness, definiteness, subjects, topics, and point of view. Subject and topic. 25-56. New York: Academic Press.

Chafe, W. 1980. The pear stories: Cognitive, cultural, and linguistic aspects of narrative production. Norwood, N. J.: Ablex. 
Chambers, C. G., \& Smyth, R. 1998. Structural parallelism and discourse coherence: A test of centering theory. Journal of Memory and Language 39(4). 593-608. https://doi.org/10.1006/jmla.1998.2575.

Christensen, M. B. 2000. Anaphoric reference in spoken and written Chinese narrative discourse. Journal of Chinese Linguistics 28(2). 303-336.

Clancy, P. M. 1980. Referential choice in English and Japanese narrative discourse; In W. Chafe (ed.), The pear stories: Cognitive, cultural and linguistic aspects of narrative production. 127-202. Norwood, NJ: Ablex.

Crawley, R. A., \& Stevenson, R. J. 1990. Reference in single sentences and in texts. Journal of Psycholinguistic Research 19(3). 191-210. https://doi.org/10.1007/bf01077416.

Creider, C. A. 1979. On the explanation of transformations. In T. Givón (ed.), Discourse and syntax (pp. 3-21). New York: Academic Press.

Davison, A. 1984. Syntactic markedness and the definition of sentence topic. Language, 60(4), 797-846. https://doi.org/10.2307/413799.

Givón, T. 1983. Topic continuity in discourse: A quantitative cross-language study. Philadelphia: John Benjamins.

Gundel, J. K., Hedberg, N., \& Zacharski, R. 1993. Cognitive status and the form of referring expressions in discourse. Language 69(2). 274. https://doi.org/10.2307/416535.

Hartshorne, J., \& Snedeker, J. 2013. Verb argument structure predicts implicit causality: The advantages of finer-grained semantics. Language and Cognitive Processes 28(10). 14741508. https://doi.org/10.1080/01690965.2012.689305.

Hinds, J. 1983. Topic continuity in Japanese. In T. Givón (ed.), Topic continuity in discourse: A quantitative cross-language study. 47-93. Philadelphia: John Benjamins.

Huang, C. T. J. 1999. Chinese passives in comparative perspective. Tsing Hua Journal of Chinese Studies 29(4). 423-509.

Hurewitz, F. 1998. A quantitative look at discourse coherence. In Walker, M., Joshi, A., Prince, E. (ed.), Centering theory in discourse. 273-291. Wotton-under-Edge, UK: Clarendon Press.

Kehler, A. 2002. Coherence, reference, and the theory of grammar. Stanford, CA: CSLI.

Kehler, A., \& Rohde, H. 2013. A probabilistic reconciliation of coherence-driven and centering-driven theories of pronoun interpretation. Theoretical Linguistics 39(1). 1-37. https://doi.org/10.1515/tl-2013-0001.

Lambrecht, K. 1994. Information structure and sentence form: Topic, focus, and the mental representations of discourse referents, Cambridge: Cambridge University Press.

Rohde, H., \& Kehler, A. 2014. Grammatical and information-structural influences on pronoun production. Language, Cognition and Neuroscience 29(8). 912-927. http://doi.org/10.1080/01690965.2013.854918.

Simpson, A., Wu, Z., \& Li, Y. 2016. Grammatical roles, coherence relations, and the interpretation of pronouns in Chinese. Lingua Sinica (2(1). 1-20. https://doi.org/10.1186/s40655016-0011-2.

Ueno, M., \& Kehler, A. 2016. Grammatical and pragmatic factors in the interpretation of Japanese null and overt pronouns. Linguistics 54(6), 1165-1221. https://doi.org/10.1515/ling2016-0027. 